\title{
A comparison of deflexions in composite beams having full and partial shear connection
}

\author{
J. G. FRODIN, R. TAYLOR \& J. W. B. STARK
}

\section{Professor R. P. Johnson, University of Warwick}

The computations in the Paper provide further support for the use of partial shear connection in composite beams in buildings. The Authors comment that their findings are 'completely at variance' with those of May and myself, ${ }^{3}$ but do not explain why.

41. The reason is not that our analysis 'was approximate only' ( $\$ 9)$. Both sets of computations used linear partial-interaction analysis of simply supported beams with uniformly spaced shear connectors, and can be assumed to be exact. The differences lie in the initial assumptions made, and in the interpretation of the results.

42. Our study used centre point loading because this was found to give more adverse results than the uniformly distributed loading used by the Authors. The effects of loadings that occur in practice will normally lie between these two. Our calculations used loads corresponding to $M_{\mathrm{u}} / 2$, as compared with $M_{\mathrm{up}} / 1.5$ used in the Paper. This should make little difference because $M_{\mathrm{up}} / M_{\mathrm{u}}$ normally lies between $0 \cdot 8$ and $1 \cdot 0$. Both studies used a wide range of shear connector stiffnesses, covering the practical range.

43. Our conclusions were based on results equivalent to those for $V_{1} / V_{F}$ (Fig. 3), not $V_{i} / V_{1}$ (Fig. 4). It was not considered that $V_{i} / V_{1}$ ratios were 'the most relevant' (\$35) because virtually all existing experience is with beams with full shear connection. The additional deflexion due to slip is always neglected in design, and seems not to occur in practice, probably because of bond between the steel beam and the concrete slab, although it does occur in laboratory tests. ${ }^{*}$ Until experience shows whether this additional stiffness can also be relied on in beams with, say, $50 \%$ shear connection, it seems prudent to neglect it when designing such beams.

44. It was this lack of experience of the long-term behaviour of beams with partial shear connection that led May and myself to discount the favourable evidence from short-term deflexions given in our fig. 8, and to base our conclusions on the line EF $(\alpha=0.5)$ in that diagram. If instead $\alpha$ is taken as 0.25 , which that evidence would support, then the maximum value of our ratio $C$ (equivalent to $V_{t} / V_{F}$ in the Paper) is reduced from 1.43 to 1.07, and lies below 1.0 in all but extreme cases. Most of the computed values that lie above $\alpha=0.25$ in our fig. 5 correspond to combinations of the variables listed in our table 1 that are more adverse than those considered in the Paper.

45. I would gladly accept the useful and simple recommendation of $\S 39$ if it can be supported by evidence of the long-term behaviour in service of beams designed with less than $60 \%$ shear connection. I understand that such evidence may be available in the Netherlands. 
Mr D. G. E. Smith, Scott Wilson Kirkpatrick and Partners

The conclusions of the Paper will be welcomed by everyone concerned by the complexity of design in composite construction. How can they be applied to unpropped construction in view of the likelihood of this form of construction with partial interaction design?

47. The deflexion of beams designed by partial interaction is probably one of the least predictable quantities in composite construction. The most unpredictable single factor is the strain level in a shear connector at a high proportion of its failure load. Menzies' tests on stud shear connectors, ${ }^{6}$ on which the analysis is based, were relatively few in number and probably do not reflect the whole spectrum of behaviour-particularly at high load levels. It is possible therefore that the method presented may be unconservative. Another unconservative factor is that the loading on beams is assumed to be uniform-a condition which in practice is never strictly satisfied. Its contravention will produce proportionately larger deflexions than in full interaction design.

48. The effect of friction across the steel-concrete interface is neglected in both the method proposed by the Authors and in the method of Johnson and May. ${ }^{3}$ This factor is absent in push-out tests and provides a hidden factor of safety for top-loaded beams. It is therefore likely that the new method may be sufficiently conservative for design purposes.

49. Unfortunately the design method presented is not supported by experimental evidence, although tests on beams with partial shear connection have been described in references 9 and 10 .

\section{Mr Frodin, Mr Taylor and Mr Stark}

Professor Johnson suggests that one of the essential differences in our viewpoints is whether $V_{1} / V_{\mathrm{F}}$ or $V_{1} / V_{1}$ should be regarded as the criterion for the basis of the comparison. We do not agree. If this were the case the resulting conclusions would be the same as our analyses have shown that the values of both $V_{i} / V_{\mathrm{F}}$ and $V_{1} / V_{1}$ decrease with a decrease in the degree of shear connection.

51. Although Professor Johnson is correct in considering that his and May's computational results were approximately equivalent to our ratio $V_{1} / V_{\mathrm{F}}$, he is not correct in considering that their overall results are based on this ratio. Their conclusions regarding span/depth ratios are based on the equivalent of rather complicated ratios which improve the position of beams with full shear connection and rather worsen the position of beams with partial shear connection. For example, compare their design line EF in their fig. 5 with their computational results which, it was stated, for practical beams lie between curve $C D$ and the hatched area.

52. Professor Johnson's point regarding bond in justification of this procedure seems to be fallacious. If the steel-concrete bond will stiffen the beam with full shear connection, there is no reason to suppose that the same bond will not also stiffen the same beam with partial shear connection. In fact in the beam with partial shear connection the service load will be lower, resulting in lower bond stresses at the steelconcrete interface. In the work by Ansourian and Roderick ${ }^{\mathbf{B}}$ the laboratory beams analysed had a thick layer of grease at the interface of steel and concrete. It is not therefore surprising that slip did occur in those beams. We agree with Mr Smith that friction would always act in normal beams to provide an extra hidden factor of safety.

53. Mr Smith draws attention to the most approximate part of our analysis: the stiffness of the shear connectors. Although we used average values we did point out the considerable variation of connector forces that can occur. We felt at the time that our approximation in this regard was warranted in view of the other factors involved and it is gratifying that $\mathrm{Mr}$ Smith also concludes that the method may be sufficiently conservative for design purposes.

54. Professor Johnson does not consider his and May's previous analysis was approximate. Apart from the above major approximation regarding their design line, we would refer him to their derivation of their factor $C$ where they use the phrases ' unlikely to exceed $30 \%$ ' and 'hence a safe (upper bound) value of $C$ is found by assum- 
ing ... Moreover they state that 'the values (of span:depth ratios) may be conservative in particular cases owing to the assumptions made in the derivation ... .

55. Indeed it was our recognition of the overall conservatism of the previous paper that led us to carry out what we consider to be a more relevant analysis. For example, it seems hardly relevant to argue that under certain circumstances a beam of partial shear connection may have greater deflexion than the corresponding beam of full shear connection when neither of these deflexions is near the limiting value. The point regarding concentrated midspan loading versus uniformly distributed loading raised by both Professor Johnson and $\mathrm{Mr}$ Smith comes into this category, because for full interaction and the same maximum bending moment the beam having the uniformly distributed loading has a deflexion $25 \%$ higher than the concentrated load case.

56. $\mathrm{Mr}$ Smith raises the question of unpropped construction. Although our calculations related only to propped construction, we believe the same general conclusion would apply to unpropped construction. We also believe that the additional variables involved in unpropped construction make the use of span/depth ratios cumbersome and the calculation of the deflexions would seem more appropriate. Even in the case of beams with partial shear connection simplified methods of calculation are possible for unpropped beams.

\section{References}

8. ANSOURIAN P. and RODERICK J. W. The analysis of composite beams. School of Civil Engineering, University of Sydney, 1977, Research Report R309.

9. Brassinga H. E. and Stark J. W. B. Tests on small-scale beams. (In Dutch.) Institute TNO for Building Materials and Building Structures, Delft, 1972, Report BI-71-52.

10. McGarraugh J. B. and Baldwin J. W. Lightweight concrete-on-steel composite beams. Engng J. Am. Inst. Steel Constr., 1971, 8, July, 90. 